\title{
Negócios Combinados: modos de prover a escola pública primária (em fins do século XIX e início do XX) ${ }^{1}$
}

\section{Arranged sales: forms of supplying public elementary schools (in the late 19th and early 20th centuries)}

\author{
Gizele de Souza* \\ Vera Lucia Gaspar da Silva**
}

\begin{abstract}
RESUMO
Este texto é dedicado à apresentação de dados e análises que têm origem em investigações que se ocupam da cultura material escolar. Nele nos concentramos na identificação e exame de modos de provimento material que foram se organizando junto ao projeto de constituição da escola pública primária. Trabalhamos com a premissa de que a constituição da escola primária pode ser investigada e compreendida por diferentes vias: a composição material é uma delas. Na direção de estudos da historiografia educacional, defendemos a perspectiva de que o projeto de escolarização de massas no Brasil necessitou de uma articulação fecunda com setores comerciais, que participaram da tarefa de produzir o aparato material que sustentaria a edificação do projeto de escolarização da infância (em fins de século XIX e início do XX).
\end{abstract}

1 Discussão inicial sobre o tema foi apresentada pelas autoras no Painel "Cultura material escolar: industria y renovación escolar”, integrado à programação do XIII Congreso Iberoamericano de Historia de la Educación Latinoamericana - CIHELA, organizado pela Sociedad Uruguaya de Historia de la Educación | SUHE e realizado em Montevideo / Uruguay entre 28 de fevereiro e 3 de março de 2018. As pesquisas que estão na origem desta produção recebem apoio financeiro e institucional do CNPq, da CAPES, da FAPESC / UDESC e da UFPR.

* Universidade Federal do Paraná. Setor de Educação. Programa de Pós-Graduação em Educação. Núcleo de Estudos e Pesquisas em Infância e Educação Infantil (NEPIE). Curitiba, Paraná, Brasil. E-mail: gizelesouza@ufpr.br. http://orcid.org/0000-0002-6487-4300.

** Universidade do Estado de Santa Catarina. Programa de Pós-Graduação em Educação. Grupo de Pesquisa Objetos da Escola. Florianópolis, Santa Catarina, Brasil. E-mail: vera.gaspar. udesc@gmail.com. https://orcid.org/0000-0003-2957-5708. 
Sustentamos também que, em concomitância a este grande comércio que se estabelecia, havia formas mais simplificadas de provimento envolvendo relações diretas com sujeitos da própria comunidade, como aquelas nas quais o professor dirigia a encomenda de determinados objetos escolares a um artesão local e, posteriormente, negociaria o ressarcimento com o Estado. Como base empírica utilizamo-nos de fontes como legislação escolar, relatórios, correspondências de governo e jornais em circulação no período. Como ferramenta analítica, adotamos a perspectiva teórico-metodológica que considera a ideia de cultura material, representação e circulação na relação entre instrução pública primária e o seu provimento.

Palavras-chave: Provimento Material Escolar. Cultura Material Escolar. Instrução Primária.

\begin{abstract}
This article presents data and analyses that originate in studies of the material culture of schools. It focuses on the identification and examination of forms of providing educational materials that were organized in conjunction with the project for establishing public primary [elementary] schools. We work with the premise that the constitution of primary schools can be investigated and understood by different means: and their material composition is one of them. In the line of historiographic studies of education, we defend the perspective that the project for the implementation of mass education in Brazil required a deep articulation with commercial sectors that participated in the task of producing the material apparatus that would sustain the mounting of childhood education (in the late 19th and early 20th centuries). We also affirm that, concomitantly to the large commercial demand that was established, there were more simplified forms of supplying school materials involving direct relations with individuals from the community, such as those in which a teacher sent a request for certain school objects to a local artisan and would later negotiate payment with the state. The empiric base for the study used sources such as laws concerning schools, reports, government correspondence and newspapers in circulation at the time. As an analytical tool we adopt a theoretical-methodological perspective that considers the idea of material culture, representation and circulation in the relation between public elementary education and the provision of materials for its execution.

Keywords: Educational material supply. Material culture of schools. Elementary education.
\end{abstract}




\section{Introdução}

Este texto é dedicado à apresentação de dados e análises que têm origem em investigações que se ocupam da cultura material escolar. Nele nos concentramos na identificação e exame de modos de provimento material que foram se organizando junto ao projeto de constituição da escola pública primária. Trabalhamos com a premissa de que a constituição da escola primária pode ser investigada e compreendida por diferentes vias: a composição material é uma delas.

Já temos acumulado uma significativa produção na área que permite afirmar que o estudo sobre a cultura material é potente, não somente para evidenciar objetos e processos presentes no passado das escolas, mas também que este modo de abordá-las pode ser revelador de mecanismos e práticas pedagógicas e comerciais, que foram se engendrando para fins de edificar e prover a escola pública primária. Embora nos concentremos aqui na realidade brasileira, com estreitamento para os estados de Santa Catarina e Paraná, localizados na região sul do Brasil, intentamos estabelecer diálogo com outras realidades, como por exemplo Minas Gerais e Goiás, de modo a estabelecer pontos de conexão mais ampliados na constituição desta importante agência de formação - a escola, e desdobramentos que este invento social pode ter provocado nas relações e na organização social. Assim, trabalhamos com duas premissas que se relacionam, mas não se sobrepõem.

$\mathrm{Na}$ direção de estudos da historiografia educacional, defendemos a perspectiva de que o projeto de escolarização de massas no Brasil necessitou de uma articulação fecunda com setores comerciais, que participaram da tarefa de produzir o aparato material que sustentaria a edificação do projeto de escolarização da infância (em fins de século XIX e início do XX).

Sustentamos também que, em concomitância a este grande comércio que se estabelecia, havia formas mais simplificadas de provimento material escolar envolvendo relações diretas com sujeitos da própria comunidade, como aquelas nas quais o professor dirigia a encomenda de determinados objetos escolares a um artesão local e, posteriormente, negociaria o ressarcimento com o Estado.

Tais premissas corroboram para a tese que aqui defendemos acerca da existência de negócios combinados, traduzidos por modos diversos nos processos de contratação, negociação e provimento material da escola primária no Brasil, em destaque para as realidades do Paraná e Santa Catarina.

Trabalhamos com uma base empírica que contempla fontes relativas a legislação escolar, relatórios, correspondências de governo e jornais em circulação no período, qual seja, fins do XIX e início do século XX. Como ferramenta 
analítica, utiliza-se da perspectiva teórico-metodológica que considera a ideia de cultura material, representação e circulação na relação entre instrução pública primária e o seu provimento. A reflexão apresentada por Roger Chartier auxilia na qualificação do sentido que aqui utilizamos para disputas de interesses. Diz ele:

As percepções do social não são, de forma alguma, discursos neutros: produzem estratégias e práticas (sociais, escolares e políticas) que tendem a impor uma autoridade à custa de outros, por elas menosprezados, a legitimar um projeto reformador ou a justificar, para os próprios indivíduos, as suas escolhas e condutas. Por isso esta investigação sobre as representações supõe-nas como estando sempre colocadas num campo de concorrências e de competições cujos desafios se enunciam em termos de poder e de dominação. As lutas de representações têm tanta importância como as lutas econômicas, para compreender os mecanismos pelos quais um grupo impõe, ou tenta impor, a sua concepção do mundo social, os valores que são os seus, e o seu domínio. Ocupar-se dos conflitos de classificações ou delimitações, não é, portanto, afastar-se do social - como julgou durante muito tempo uma história de vistas demasiado curtas - muito pelo contrário, consiste em localizar os pontos de afrontamento, tanto mais decisivos quanto menos imediatamente materiais (CHARTIER, 2002, p. 17, grifos nossos).

Como anteriormente anunciado, o estudo que empreendemos utiliza fontes variadas e, neste sentido, temos ciência sobre a natureza distintiva dos contextos das fontes mencionadas, as finalidades, linguagens, proponentes, destinatários... mas para esta pesquisa o objetivo residiu no entrecruzamento de dados localizados nestas fontes a fim de dar visibilidade aos modos como o provimento material escolar foi se organizando na perspectiva de atender a escola primária. Com isto pretendemos, além de fomentar e fortalecer uma perspectiva de análise, apoiada na cultura material escolar, contribuir no debate que busca ampliar as lentes que analisam a constituição da escolarização da infância, fortalecendo a ideia da pluralidade nos modos de organização destas instituições e contribuindo na desconstrução de uma ideia de linearidade ou homogeneização do processo de sua constituição, especialmente no caso brasileiro, cujas províncias e mais tarde os estados desenvolveram este aparato com certa autonomia, na composição de formas diversas de organização escolar. 


\section{A mobília escolar em negócios combinados: carpinteiros, professores, penitenciárias e comerciantes/fábricas}

Em fins do século XIX e início do XX, as províncias e estados brasileiros se debatem acerca da institucionalização do ensino obrigatório no ensino primário e suas consequências acerca do provimento escolar. O Superintendente Geral do Ensino do Paraná, Vitor Ferreira do Amaral e Silva, expõe esta preocupação afirmando:

Para que os sacrifícios pecuniários que o Estado faz para manter escolas sejam bem compensados, é mister que seja instituída a obrigatoriedade do ensino, a favor da qual serei sempre acérrimo propugnador. Contra o ensino obrigatório levantam-se alguns, em extremo ciosos pelas liberdades públicas, dizendo que é uma violência ou restrição que se faz à liberdade do cidadão (AMARAL E SILVA. Relatório, 1893, p. 42)².

A institucionalização, o acesso e a frequência escolar são processos que se constituem em meio a grandes e longos debates e que alteram significativamente a vida das famílias e das crianças. A instalação deste "invento social" - a escola - se dá em quadros de disputas e tensões. Para António Nóvoa (2006), a escola se torna um

[...] componente essencial do Estado-nação e de um ideal de sociedade produzido e difundido, sistematicamente, por uma série de atores e agências. Ele não é fruto do acaso ou de um processo imprevisível. Ao contrário, é o resultado da conjugação de vários esforços, conduzidos por intelectuais, homens de Estado e educadores ${ }^{3}$ (NÓVOA, 2006, p. 197, grifo do autor).

2 Utilizamos neste texto a norma padrão da língua escrita atual.

3 Tradução livre do original em francês "L'école de masse est une composante essentielle de l'État-nation et d'un idéal de société qui a été produit et diffusé, systématiquement, par toute une série d'acteurs et d'agences. Ellen'est pas le fruit du hasard ou d'un processus imprévisible. Bien au contraire, elle est le résultat de la conjugaison de plusieurs efforts, menés par des intellectuels, des hommes d'État et des éducateurs ..:" Nesta reflexão António Nóvoa faz referência ao estudo de John Meyer, David Kamens et Aaron Benavot, School knowledge for the masses - World models and national primary curricular categories in the twentieth century, Washington/London, The Falmer Press, 1992, p. 9-10. 
António Nóvoa se alia aos autores que reconhecem a existência de um projeto mundial de escolarização da infância que se organiza e se difunde com força na virada do século XIX para o século $\mathrm{XX}^{4}$. Na investigação que toma por referência províncias e estados brasileiros podemos localizar aspectos comuns. O já citado Superintendente Vitor Ferreira do Amaral e Silva narra, em fins do século XIX, sua preocupação acerca do provimento das escolas e do desafio diante deste contexto da obrigatoriedade escolar. "As escolas públicas em geral acham-se mal providas de moveis, que ou são insuficientes, ou imprestáveis. Cotidianamente esta Superintendência recebe reclamações de professores, pedindo mobília para escolas e livros para distribuir aos alunos pobres" (AMARAL e SILVA. Relatório, 1893, p. 6).

Mas, se por um lado o aparelho estatal, através de seus representantes, expressa preocupações desta natureza, por outro, interessa-nos destacar que, por meio da pesquisa empírica, localizamos o papel do professor para além de protagonizar os reclames junto às autoridades acerca da precariedade dos móveis e condições de sua escola. Em fins do século XIX e no decorrer das primeiras décadas do $\mathrm{XX}$, encontramos professores como responsáveis pela fabricação de móveis e/ou solicitantes de móveis a marceneiros em várias localidades brasileiras. Em ofício da professora de primeiras letras Leocádia Maria da Rocha, na cidade de Antonina, no Paraná, ao Inspetor Geral da Instrução Pública, encontra-se o pedido de autorização para mandar fazer a mobília para a sua escola (ROCHA, Leocádia Maria da, DEAP, 1872, AP. 0396, p. 40). Neste mesmo ano, 1872, outro professor - Herculano José Carneiro de Mendonça - da província de Goiás, solicita “que lhe seja paga mensalmente a quantia de $6 \$ 000$ rs, metade do aluguel por que encontrou uma casa para a escola e para a sua residência, e bem assim autorização para mandar fazer a mobília necessária à mesma escola" (CORREIO OFFICIAL. Goias, 03/02/1872, n. 405, p. 2).

Na mesma província de Goiás, nos primeiros anos do século $\mathrm{XX}$, no expediente da Secretaria de Finanças Pública foi remetido ao Delegado Literário de Santa Luzia o recibo do professor da escola do sexo masculino, autorizando-o a "mandar fazer a mobília de que carece a referida escola" (GOYAZ, 17/06/1903, n. 766, p. 2).

Décadas depois em Minas Gerais, por meio de uma exposição de trabalhos escolares, organizada pela Secretaria do Interior, foi examinada por um júri “a

4 Destacamos aqui o impacto da obra organizada por António Nóvoa e Jürgen Schriewer com o título A Difusão Mundial da Escola (Lisboa: EDUCA, 2000). 
mobília escolar de tipo novo, criado pelo professor Arthur Joviano" (O PHAROL. Juiz de Fora, 21/02/1923, n. 240, p. 1), que esteve até 1922 à frente da Escola Normal Modelo de Belo Horizonte (MENSAGENS, 1923, n. 1, p. 218).

Com os excertos acima, percebemos a movimentação de professores frente aos desafios da instituição da obrigatoriedade escolar e das respectivas exigências para com o provimento da escola primária; ora solicitando mobília e angariando pessoas que pudessem viabilizar tais materiais, por vezes eles mesmos à frente da fabricação da mobília escolar, demonstrando assim que a cultura material não só configura a vida e o cotidiano da escola, mas também o próprio oficio docente (FRANÇA, 2019). Tais ações de professores podem ser compreendidas no contexto daquilo que Agustín Escolano Benito (2000) nomeia de "cultura prática da escola".

Desafios postos aos professores primários, de equilibrar e atender exigências e cobranças advindas das autoridades e da legislação escolar, em responder às suas próprias expectativas frente ao oficio docente, se fizeram presentes no contexto das províncias e estados brasileiros, como também em outros lugares, mesmo que com colorações e condições distintas. Da perspectiva da historiografia espanhola, Agustín Escolano Benito (2000) apresenta algumas situações, às quais os professores tiveram que enfrentar e responder:

- La disposición y uso de los espacios en que se instalaron las escuelas (no siempre con arquitectura $a d$ hoc, y a menudo con innumerables precariedades).

- La gestión del tiempo, incluidas las asignaciones horarias a las rúbricas curriculares y los ritmos del proceso, además del control de su regulación. [...] - La organización de la marcha de la clase según criterios y reglas de disciplina tomadas de la experiencia propia o corporativa. [...]

- La adopción de métodos y procedimientos específicos, inspirados en la tradición y en la inventiva propia para la enseñanza de la lectura, la escritura, el cálculo y demás saberes elementares.

- La creación de un utillaje profesional con objetos e instrumentos que con el tempo llegarían a configurar el ajuar del maestro.

- La preparación y uso de materiales, incluidos los textos y demás recursos (ESCOLANO BENITO, 2000, p. 205).

Como se vê, aos professores caberia atuar em uma gama de ações, com vistas a viabilizar o exercício do seu ofício e entendemos que a efetividade da mobília na escola constitui parte deste aparato educativo. 
Além de professores, outros personagens entram em cena na fabricação e fornecimento de mobília escolar; trata-se de marceneiros ${ }^{5}$, pequenos comerciantes e industriais.

Em jornais de Santa Catarina foi possível localizar cobranças ao Estado por fornecimento de móveis:

\begin{abstract}
Recomenda a expedição de ordem à coletoria de Nova Trento para pagar pela verba consignada no $\S 12$ do orçamento em vigor ao cidadão Luiz Valle a quantia de $45 \$$, proveniente do fornecimento de móveis feito à escola do Arrayal do Salto, conforme os documentos que se remetem (REPUBLICA. Florianópolis, 04/10/1900, n. 382, p. 1).
\end{abstract}

Outra nota registra cobrança à Secretaria da Fazenda, Viação, Obras Públicas e Agricultura do mesmo Estado, de uma dívida em favor do sr. Juvenal José de Souza pela "quantia de $280 \$$, proveniente do fornecimento de móveis à Escola de Campo Bello, no município de Lages" (REPUBLICA. Florianópolis, 26/11/1926, n. 48, p. 8).

Localizamos também cobrança à Secretaria do Interior e Justiça de Santa Catarina, para que fosse paga "ao Sr. José Eleutherio Borges, a quantia de 300\$ proveniente de fornecimento de móveis feito à escola mista de Morro Grande, no município da Laguna, regida pela professora D. Donodoria Jovelina Prates" (REPUBLICA. Florianópolis, 22/01/1927, n. 95, p. 8).

Temos ainda a "restituição feita aos srs. Wassmausdorf \& Irmão, da caução depositada para garantir a apresentação de uma proposta para fornecimento de móveis a dois Grupos Escolares" (REPUBLICA. Florianópolis, 04/06/1931, n. 184, p. 5).

Mas o que estes fragmentos de matérias em jornais catarinenses nos revelam? Os dados indiciam sobre a situação do mobiliário escolar, condições de fabricação e destinação de verbas. Evidencia-se também que, no arranjo dos negócios combinados, sujeitos como os mencionados acima - Luiz Valle, Juvenal de Souza e José Eleutherio Borges - constituem-se uns dos muitos carpinteiros, comerciantes, profissionais que atuavam, de modo local, para atender demandas provenientes de professores, inspetores e de outras instâncias do aparelho estatal, a fim de prover materialmente as escolas.

5 Gecia Aline Garcia, aluna do Mestrado, do Programa de Pós-Graduação em Educação da UFPR, sob supervisão da professora Gizele de Souza, realiza uma pesquisa que trata do itinerário moveleiro na instrução pública primária paranaense, entre fins do século XIX e XX, na qual os marceneiros constituem-se em personagens centrais. 
A literatura especializada na história da escola primária no Brasil ${ }^{6}$ já demonstrou as dissonâncias entre determinações normativas acerca do provimento material da escola e a efetivação destas exigências. Em muitos contextos as escolas eram criadas, mas não eram providas no que tange às necessidades materiais. Uma tensa relação vai constituindo este terreno para, de algum modo, pressionar o poder público na tomada de providências para a alteração do quadro de precariedades. Por meio do Relatório de 1917 assinado pelo Secretário do Estado de Instrução Pública do Paraná, observa-se que a preocupação residia em tornar

\begin{abstract}
necessário o aumento da verba orçamentária destinada ao mobiliário escolar, tão sensivelmente reduzida no corrente exercício, que esgotou-se nos primeiros meses, obrigando a abertura de créditos. Criar numerosas escolas, sem dar os meios necessários ao seu aparelhamento, é fazer obra incompleta, se não inútil (SANTOS, Enéas Marques dos. Relatório apresentado ao Exmo. Snr. Dr Affonso Alves de Camargo - Presidente do Estado. 31/12/1917, p. 11).
\end{abstract}

Esta tensão entre o exigido e o provido materialmente é "fazer obra incompleta", como expresso nas palavras do Secretário do Paraná, pois segundo sua avaliação "criar numerosas escolas, sem dar os meios necessários ao seu aparelhamento" seria incorrer em ação inacabada ou quase "inútil". O que aqui nos interessa frisar é menos a retórica da autoridade estatal no alarmismo da precariedade material, e mais o desafio que estava posto às escolas e aos seus responsáveis públicos pelo abastecimento material diante das condições muito distintas e desiguais. Lembremo-nos de que este é um momento histórico ainda em consolidação da escola pública primária brasileira ou, como afirmado nas palavras do editorial da Revista A Escola Primária, o Brasil era "uma nacionalidade que ainda se organizava” (A ESCOLA PRIMÁRIA, Rio de Janeiro, 1917, p. 1$)^{7}$. Nesta direção, entendemos que tais notícias explicitadas colaboraram

6 Num leque de possibilidades sugerimos consulta ao livro História da Escola Primária no Brasil: investigações em perspectiva comparada em âmbito nacional, organizado por Rosa Fátima de Souza, Antonio Carlos Ferreira Pinheiro e Antônio de Pádua Carvalho Lopes (Aracaju: EDISE, 2015); e também o e-book Imagens da escola primária no Brasil (1920 - 1960), de autoria de Rosa Fatima de Souza Chaloba, Marcus Levy Bencostta e Vera Lucia Gaspar da Silva (1. ed. Florianópolis / SC: Editora da UDESC, 2018). Disponível em: https://issuu.com/fernandafelizari/ docs/projeto_livro_vera_gaspar_fim.

7 Esta afirmação compõe uma avaliação que a Revista do Rio de Janeiro A Escola Primária realiza no seu editorial intitulado "Caminho percorrido", em função do primeiro ano de publicação do periódico. 
na perspectiva de entender "como os objetos escolares podem constituir-se em locus de negociação entre professores e autoridades de ensino, em espaços de tensão e afirmação do lugar da escola no processo de escolarização da infância" (PERES, SOUZA, 2013, p. 59). Essa mesma documentação coligida é potente para investigar a composição dos 'arranjos' (aqui não na acepção do improviso, mas das combinações feitas) que cada província e estado brasileiro foi pleiteando organizar, contando com colaboradores como marceneiros e comerciantes atuantes no atendimento de encomendas de móveis a grupos escolares e variadas escolas, como as catarinenses anteriormente mencionadas.

Paralelamente à atuação dos marceneiros e pequenos comerciantes, também localizamos, no decorrer das duas primeiras décadas do século XX, outra frente que entra em cena neste processo de fabricação de móveis escolares - são as penitenciárias. Vejamos alguns exemplos. Em junho de 1909, quando Jayme dos Reis assumiu interinamente a Direção da Instrução Pública do Paraná em substituição a Arthur Pedreira de Cerqueira, uma das ações para melhoria da mobília foi substituir em algumas escolas os 'bancos-carteiras' existentes por outros novos, como realizado no Grupo Xavier da Silva, no Grupo Escolar de Castro, no Ginásio Paranaense etc. A justificativa dada pelo diretor interino para o não fornecimento para as outras tantas escolas que permaneceram à míngua foi a escassez do tempo e a pequena produção do mobiliário pela Penitenciária do Estado (REIS, Jayme. Relatório, 1909, p. 65).

8 Para uma discussão mais aprofundada sobre a constituição da instrução pública do Estado do Paraná e os efeitos para a organização do ensino, ver a tese Instrução, o talher para o banquete da civilização: cultura escolar dos jardins-de-infância e grupos escolares no Paraná, 1900-1929, de autoria de Gizele de Souza, 2004 (Doutorado em Educação História Política Sociedade. Pontifícia Universidade Católica de São Paulo, PUC/SP, Brasil). 


\section{FIGURA 1: OFICINA DE MARCENEIROS - PENITENCIÁRIA AHÚ ${ }^{9}$}

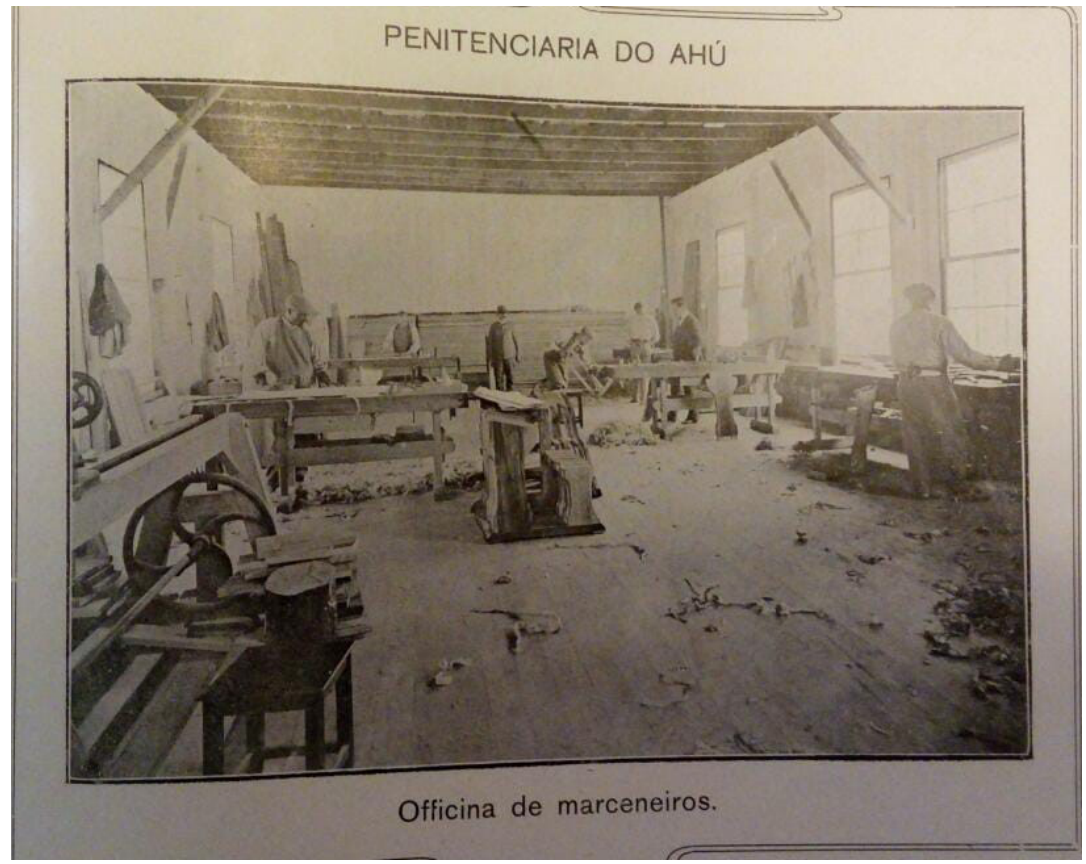

FONTE: CARVALHO FILHO, João Baptista da Costa. Relatório do Chefe da Polícia do Estado, 1909, p. 109.

Ainda no contexto paranaense, o Inspetor Geral do Ensino - Cesar Prieto Martinez - descreve em seu relatório, em 1921, enviado ao Secretário Geral de Estado, Marins Alves de Camargo, que "apesar dos milhares de carteiras distribuídas pelo atual Governo aos grupos escolares isolados do Estado, ainda assim há centenas de estabelecimentos que carecem de mobiliário" [...] e que, "além das encomendas feitas a diversas fábricas desta capital, também temos tido fornecimentos das oficinas da Penitenciária do Estado" (MARTINEZ, Cesar Prieto. Relatório, 1921, p. 29-30).

Em Minas Gerais, em anúncio de 1913, encontramos a informação de que "a Penitenciária da cidade de Ouro Preto está também fornecendo ainda carteiras duplas, fabricadas pelos detentos, até esgotar-se o stock de pés de ferro existente"

9 Agradecemos à Gecia Aline Garcia pela localização e disponibilização desta fonte. 
(BRANDÃO, Julio Bueno. Mensagem dirigida pelo Presidente do Estado ao Congresso Mineiro em sua $3^{\mathrm{a}}$. Sessão Ordinária da $6^{\mathrm{a}}$. legislatura, 1913, p. 48).

O trabalho desta pesquisa nos fornece "indícios", "pistas" (GINZBURG, 1989 , p. 150) para sustentar que os governos estaduais, para dar conta da empreitada de prover as escolas públicas primárias, lançaram mão de inúmeras "estratégias" (CERTEAU, 2009, p. 87), nas quais a combinação das frentes de demandas por material escolar com a participação de sujeitos e instituições distintas, resultou, num plano de tendências, em arranjos diversos:

- professores em relação direta com autoridades governamentais na cobrança por autorização de encomenda de mobília para as escolas, assim como no repasse do pagamento por mobília já confecionada;

- professores em relação direta com marceneiros e pequenos comerciantes, seja no empréstimo de materiais escolares, seja na aquisição de mobília e livros;

- o Estado delegando a inspetores e professores a resolução de impasses frente ao provimento material, provocando situações nas quais professores buscam parcerias com outros colegas e escolas existentes na localidade a fim de equipar, mesmo que parcialmente, as suas escolas;

- o fornecimento de determinados materiais às escolas primárias pelo Estado a despeito de demandas provenientes dos professores.

Estas configurações, em casos empíricos específicos, podem assumir oscilações e movimentos que combinem e integrem muitas das ações acima descritas e resultem em outras composições.

Neste movimento identificamos, além dos já apontados, a atuação de industriais nesta empreitada de abastecimento material escolar. Em um Relatório do Governo de Minas Gerais, localizamos a seguinte indicação:

Atualmente, há dois únicos contratos para o fabrico de carteiras escolares: um firmado com a Usina Wigg, de Miguel Burnier, para a feitura de hastes de ferro (pés), varões e parafusos; outro, firmado com os srs. Corrêa\&Corrêa, industriais residentes em Juiz de Fora, para a feitura das peças de madeira, adaptáveis àqueles pés (BRANDÃO, Julio Bueno. Mensagem [...], 1913, p. 48).

Se, pela informação apresentada acima, identificamos que o governo de Minas tinha contrato com industriais das empresas Corrêa \& Corrêa e da Usina Wigg, as fontes consultadas nos revelam que este tipo de relação também esteve presente em outras partes do país. Destacamos aqui a atuação da firma Paschoal Simone que atuava no fornecimento de materiais escolares em Santa Catarina e 
no Paraná. Em correspondência de 31 de março de 1920 (mas assinada ao final do documento de 8 de abril de 1920), o proprietário da firma, Paschoal Simone ${ }^{10}$, solicita à Secretaria do Interior do Paraná o pagamento referente aos diversos objetos fornecidos àquela repartição pública. Pelas imagens reproduzidas abaixo (Figuras 1 e 2), vemos que a firma de Paschoal Simone \& Cia era proprietária da Livraria Econômica, que prestava serviços de papelaria, tipografia, encadernação, fabricação e importação direta.

FIGURA2: CABEÇALHO DACORRESPONDÊNCIADA 'LIVRARIAECONÔMICA', DE PROPRIEDADE DA FIRMA PASCHOAL SIMONE.

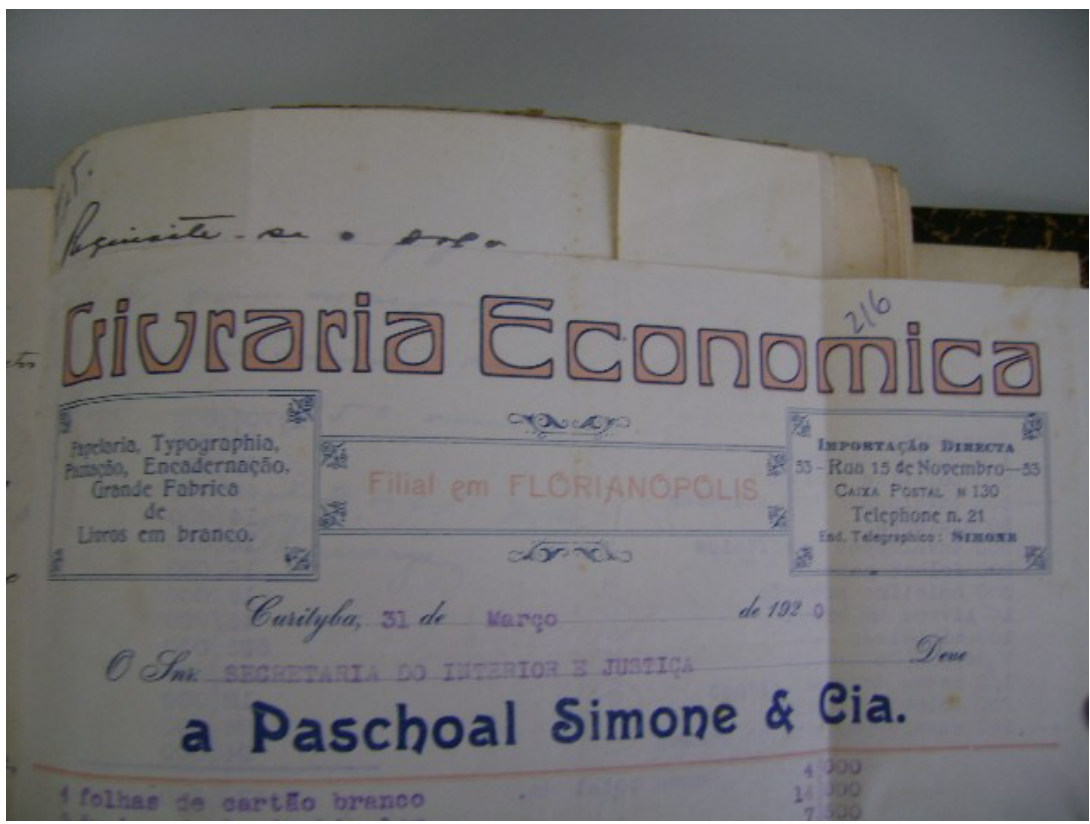

FONTE: Correspondência de Paschoal Simone à Secretaria do Interior. DEAP. AP 1813, 31 de março de 1920, p. 216.

10 Paschoal Leme falece em 30 de janeiro de 1940 aos 78 anos, segundo informações do jornal $A$ NOTÍCIA, de 31 de janeiro de 1940, n. 3400, p. 5. 
FIGURA 3: LISTAGEM DE MATERIAIS FORNECIDOS PELA FIRMA PASCHOAL SIMONE AO GOVERNO DO ESTADO DO PARANÁ.

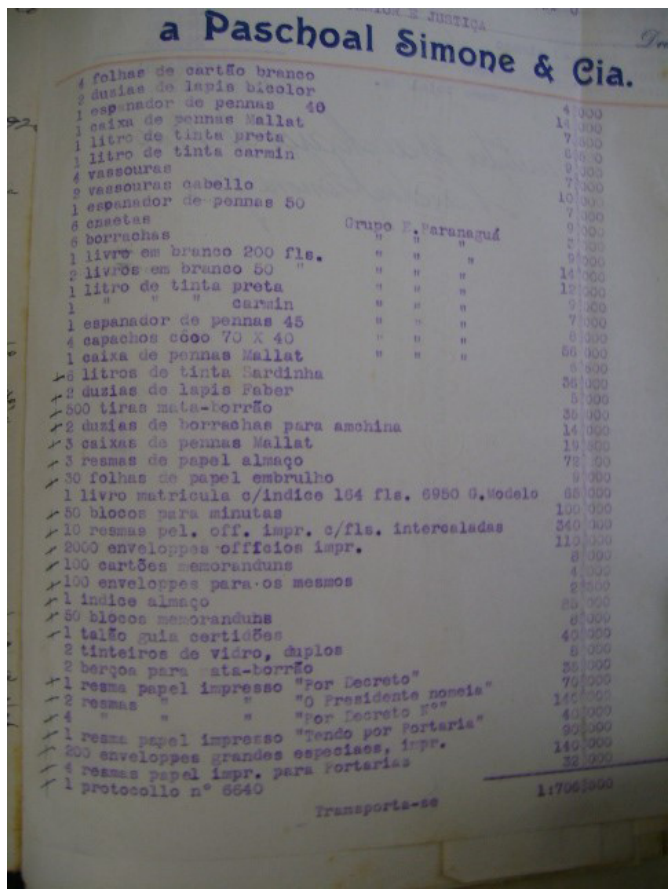

FONTE: Correspondência de Paschoal Simone à Secretaria do Interior. DEAP. AP 1813, 31 de março de 1920, p. 216.

As fontes provenientes do Arquivo Público do Paraná e da imprensa periódica nos informam que, no decorrer da década de 1920, a referida empresa forneceu incontáveis objetos e materiais escolares para as escolas paranaenses e catarinenses. Em 1931, a firma ganha várias concorrências para fornecer material tanto à Diretoria de Instrução Pública, comercializando livros da Série H. Fontes e papel, lápis e caneta (REPUBLICA. Florianópolis, 13/02/1931, p. 2), como material de expediente para a Secretaria de Estado dos Negócios da Fazenda, Viação, Obras Públicas e Agricultura (REPUBLICA. Florianópolis, 25/01/1931, p. 4).

Embora as fontes acima percorram o período dos anos 1920 e 1930, a firma de Paschoal Simone já comparece nos anúncios de publicidade, por meio da sua 'Livraria Moderna' desde 1898, como se pode ver na Figura 4: 
FIGURA 4: ANÚNCIO DA LIVRARIA MODERNA.

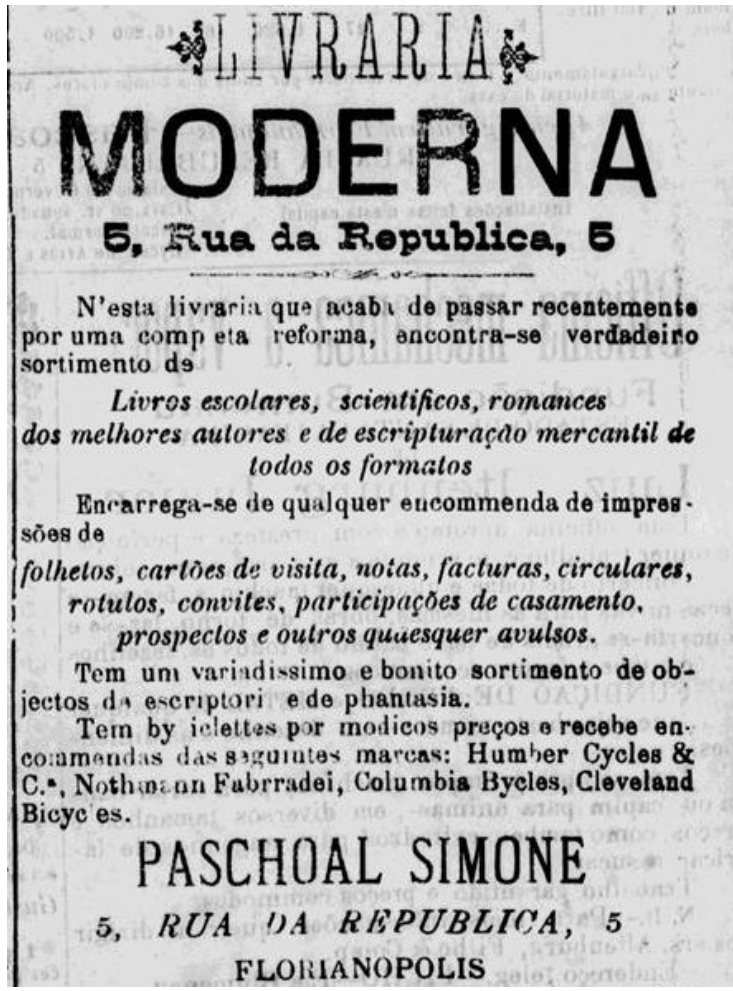

FONTE: Republica. Florianópolis, 15/12/1898, n. 268. p. 3.

Em sua dissertação de mestrado Hiassana Scaravelli (2016) captura a atuação desta firma, em Santa Catarina, junto a outras empresas no decorrer de toda a década de 1910. Afirma a pesquisadora que o "provimento do material nos anos de 1908 a 1921 foi realizado por cinco empresas: Otto Boehm e C. W. Boehm de Joinville, Paschoal Simone \& Filhos, Octávio Lobo da Silveira e Max Schrappe de Florianópolis" (SCARAVELLI, 2016, p. 91, grifo nosso). Scaravelli (2016) também nos esclarece que a Livraria Moderna era propriedade do italiano dono da Paschoal Simone \& Filhos e localizava-se na Rua Conselheiro Mafra $n^{\circ} .9$ (p. 122).

Muitas são as possibilidades de cotejamento entre os comerciantes investigados pela Hiassana Scaravelli (2016), mas um caminho potente reside no nome 
como fio condutor (GINZBURG, 1991, p. 175), perspectiva que o historiador italiano nomeia de "investigação micronominal" (p. 175), na qual poderíamos pensar a atuação da firma Paschoal Simone no fornecimento de material para escolas paranaenses e catarinenses em uma trama que localiza tanto a sua presença comercial neste cenário, como a rede que constituía com outros fabricantes e proprietários de livrarias e marcenarias e seus vínculos com o Estado, via editais de concorrência, encomendas dirigidas etc. Neste sentido, vemos um caminho promissor que rastreia pela via do nome, a atuação, as parcerias, as concorrências, os investimentos feitos e a circulação destes sujeitos e ações.

\section{Arremates Finais}

Conforme anunciado já no início, dedicamo-nos neste trabalho a examinar modos diversos de provimento da escola primária, relações estabelecidas com o Estado e estratégias que províncias e estados lançaram mão na empreitada do provimento material escolar. Entendemos que esta é uma das possibilidades de análise da instituição escolar, ancorada na perspectiva da cultura material.

A reflexão foi organizada articulando aspectos que contemplam relações entre sujeitos e instituições envolvidas no provimento material das escolas, podendo compor esta trama os professores, os inspetores, autoridades de ensino, comerciantes, marceneiros, indústrias e penitenciárias.

Com a exposição de dados garimpados nas fontes e nas análises tecidas, identificamos modos de articulação de táticas e estratégias (CERTEAU, 2009) intermediando as relações entre Estado, professores e comerciantes no que tange ao esforço de prover materialmente as escolas públicas.

Tal articulação expressa os negócios combinados, aludidos no título, tanto no sentido de propostas paralelas de fornecimento às escolas, como no de acionar agentes, sujeitos e instituições distintas nesta trama político-comercialpedagógica. Nesta esteira, vimos que o fornecimento de mobília escolar, por exemplo, pode ser efetivado em negócios combinados envolvendo carpinteiros, professores, penitenciárias, comerciantes e fábricas.

Se, em fins do século XIX e no decorrer das primeiras décadas do XX, encontramos professores como responsáveis pela fabricação de móveis e/ou solicitantes de móveis a marceneiros em várias localidades brasileiras, também identificamos outros personagens em cena na fabricação e fornecimento de mobília e itens do aparelhamento escolar, trata-se, como já indicado, de marceneiros, pequenos comerciantes, industriais e penitenciárias. Identificar 
dados que materializam este complexo jogo nos é muito caro na medida em que contribui para o alargamento da compreensão sobre os processos de constituição e consolidação da escola - e aqui dedicamo-nos à escola primária -, este "invento social" que mobilizará tantos setores e se expandirá por vários territórios conforme já indicaram muitos dos estudiosos do "fenômeno social" traduzido na "difusão mundial da escola" (NÓVOA; SCHRIEWER, 2000).

Se por um lado é possível identificar uma espécie de cruzada dos estados no sentido de instituir a escolarização da infância, por outro, um conjunto de estudos tem indicado a insuficiência - seja por escolha política, seja por questões econômicas ou mesmo nas tentativas de realizações pedagógicas - dos Estados no provimento material das escolas. Assim, para fazê-lo, uma teia de relações vai se estabelecendo, construindo aquilo que estamos aqui denominando de arranjos ou negócios combinados.

Com as indicações e análises apresentadas pretendemos fomentar e fortalecer uma perspectiva apoiada na cultura material escolar e propor um caminho investigativo que toma a materialidade escolar como locus do exame analítico. Nesta esteira, referimo-nos à ação dos agentes envolvidos no fornecimento material escolar (como professores, comerciantes, autoridades de ensino, firmas, etc) como pistas a revelar a presença e condições de um conjunto material nas escolas, bem como sobre as relações permeadas por acordos firmados, embates e tensões.

$\mathrm{O}$ estudo visa a contribuir no debate que busca ampliar as lentes que analisam a constituição da escolarização da infância, fortalecendo a ideia da pluralidade nos modos de organização destas instituições e desnaturalizando uma ideia de linearidade ou homogeneização do processo de sua constituição, especialmente no caso brasileiro.

\section{FONTES}

\section{Biblioteca Nacional Digital:}

A NOTÍCIA. Notas Sociais - Faleceu o Sr. Paschoal Simone. Florianópolis, 31/01/1940, n. 3400 , p. 5.

CORREIO OFFICIAL. Goiás, 03/02/1872, n.405, p. 2.

GOYAZ. Expediente da Secretaria de Finanças Públicas. 17/06/1903, n.766, p. 2.

O PHAROL. Juiz de Fora, 21/02/1923, n. 240, p. 1.

REPUBLICA. Florianópolis, 04/10/1900, n. 382, p. 1. 
REPUBLICA. Florianópolis, 26/11/1926, n. 48, p. 8.

REPUBLICA. Florianópolis, 22/01/1927, n. 95, p. 8.

REPUBLICA. Florianópolis, 25/01/1931, n 77, p. 4.

REPUBLICA. Florianópolis, 13/02/1931, n. 93, p. 2

REPUBLICA. Florianópolis, 04/06/1931, n. 184, p. 5.

REPUBLICA. Livraria Moderna. Florianópolis, 15/12/1898, n. 268, p. 3.

REVISTA A ESCOLA PRIMÁRIA. Caminho percorrido. Rio de Janeiro, ano $1^{\circ}$., n.12, $1^{\circ}$. Setembro de 1917.

\section{Arquivo Público do Paraná:}

Correspondência de Paschoal Simone à Secretaria do Interior. DEAP. 31/03/1920, AP. 1813, p. 216.

ROCHA, Leocádia Maria da. Correspondência ao Inspetor Geral da Instrução Publica. Paranaguá. DEAP, 1872, AP. 0396, p. 40.

\section{Relatórios e Mensagens de Governo:}

AMARAL e SILVA, Vitor Ferreira do. Relatório do Superintendente Geral do Ensino ao Secretário do Interior, Justiça e Instrução Pública. Curitiba, 4 de novembro de 1893.

BRANDÃO, Julio Bueno. Mensagem dirigida pelo Presidente do Estado ao Congresso Mineiro em sua $3^{\text {a }}$ Sessão Ordinária da $6^{\mathrm{a}}$ legislatura, 1913.

CARVALHO FILHO, João Baptista da Costa. Relatório do Chefe da Polícia ao Sr. Secretário do Interior. Typografia da Penitenciária do Ahú. Curitiba, 1909.

MARTINEZ, Cesar Prieto. Relatório do Inspetor Geral do Ensino ao Secretário Geral de Estado Marins Alves de Camargo. Curitiba, 01 de agosto de 1921.

Mensagens do Governador de Minas Gerais para a Assembleia. 1923, n. 1, p. 218.

REIS, Jayme Dormund dos. Relatório do Diretor Geral Interino da Instrução pública ao Secretário do Interior, Justiça e Instrução Pública Coronel Luiz Antonio Xavier. Curitiba, 24 de novembro de 1909.

SANTOS, Enéas Marques dos. Relatório apresentado ao Exmo. Snr. Dr Affonso Alves de Camargo - Presidente do Estado. Em 31 de dezembro de 1917, p. 11. 


\section{REFERÊNCIAS}

CERTEAU, Michel de. A Invenção do Cotidiano. 1. Artes de Fazer. Tradução de Ephraim Ferreira Alves. Petrópolis, RJ: Vozes, 2009.

CHARTIER, Roger. Por uma sociologia histórica das práticas culturais. In: CHARTIER, Roger. A História Cultural: entre práticas e representações. $2^{\mathrm{a}}$ Ed. Lisboa: Difel, 2002, p. 13-28.

ESCOLANO BENITO, Agustín. Las culturas escolares del siglo XX: encuentros y desencuentros. Revista de Educación. Espanha, Núm. Extraordinário, p. 201-218, 2000.

FRANÇA, Franciele Ferreira. Um inventário de saberes, um repertório de fazeres: modos e práticas do ofício de ensinar durante a segunda metade do séc. XIX (1856-1892). 2019. Tese (Doutorado em Educação) - Programa de Pós-Graduação em Educação. Universidade Federal do Paraná. Curitiba / PR, 2019.

GINZBURG, Carlo. Sinais: raízes de um paradigma indiciário. In: GINZBURG, Carlo. Mitos, Emblemas e Sinais: morfologia e história. São Paulo: Companhia das Letras, 1989, p. 143-179.

GINZBURG, Carlo. O nome e o como. Troca desigual e mercado historiográfico. In: GINZBURG, Carlo; CASTELNUOVO, Enrico; PONI, Carlo. A micro-história e outros ensaios. Tradução de António Narino. Rio de Janeiro: Bertrand Brasil; Lisboa: DIFEL, 1991, p. 169-178.

NÓVOA, António. La construction du «modèle scolaire» dans l'Europe du Sud-Ouest (Espagne, France, Portugal) Des années 1860 aux années 1920. Thèse de Doctorat d'Histoire. Paris: Université Paris IV - Sorbonne - École Doctorale d'Histoire Moderne et Contemporaine - Centre d'Histoire du XIXe siècle. Paris / França, 2006.

NÓVOA, António; SCHRIEWER, Jürgen (Eds). A Difusão Mundial da Escola. Lisboa: EDUCA, 2000.

PERES, Eliane; SOUZA, Gizele de. Aspectos Teóricos-Metodológicos da Pesquisa sobre a Cultura Material Escolar: (im)possibilidades de investigações. In.: CASTRO, César Augusto (Org.) Cultura Material Escolar: a escola e seus artefatos (MA, SP, PR, SC e RS) - 1870-1925. 2ª Ed. São Luís / MA: EDUFMA / Café \& Lápis, 2013, p. 43-68.

SCARAVELLI, Hiassana. Objetos à Venda: Indícios da comercialização de materiais escolares em jornais catarinenses (1908-1921). 2016. Dissertação (Mestrado em Educação) - Programa de Pós-Graduação em Educação. Universidade do Estado de Santa Catarina. Florianópolis / SC, 2016

SOUZA, Rosa Fátima de; PINHEIRO, Antonio Carlos Ferreira; LOPES, Antônio de Pádua Carvalho (Orgs.). História da Escola Primária no Brasil: investigações em perspectiva comparada em âmbito nacional. Aracaju / SE: EDISE, 2015. 
SOUZA CHALOBA, Rosa Fatima de; LEVY A. BENCOSTTA, Marcus; GASPAR da SILVA, Vera Lucia. Imagens da escola primária no Brasil (1920 - 1960). 1. ed. Florianópolis/SC: Editora da UDESC, 2018. Disponível em: https://issuu.com/fernandafelizari/ docs/projeto_livro_vera_gaspar_fim. Acesso em: 15 set. 2018.

SOUZA, Gizele de. Instrução, o talher para o banquete da civilização: cultura escolar dos jardins-de-infância e grupos escolares no Paraná, 1900-1929. 2004. Tese. (Doutorado em Educação História Política Sociedade) - Pontifícia Universidade Católica de São Paulo, PUC/SP, Brasil, 2004.

Texto recebido em 17 de maio de 2019.

Texto aprovado em 1 de julho de 2019. 